Reviews in Digital Humanities • Vol. 2, No. 12

\title{
Review: The East End Digital Library
}

\author{
Abigail Droge ${ }^{1}$ \\ ${ }^{1}$ Purdue University
}

Published on: Dec 13, 2021

DOI: $10.21428 / 3 e 88 f 64 f .7 d 145 d c b$

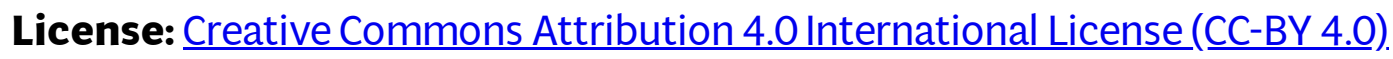




\section{Project}

The East End Digital Library: A Collection of Archives

\section{Project Directors}

Heidi Kaufman, University of Oregon

\section{Project URL}

https://eastendarchives.net/

\section{Project Reviewer}

Abigail Droge, Purdue University

\section{Project Overview}

\section{Heidi Kaufman}

The East End Digital Library: A Collection of Archives is a digital humanities project dedicated to making archives of London's 19th-century East End accessible to the public. The 19th-century East End of London is frequently read through reductive stereotypes that emphasize the region's history of crime and danger, best known, perhaps, by the enduring legend of Jack the Ripper who stalked victims in Whitechapel. Archival records suggest, however, that this region was home to important intellectual and creative activities. The East End Digital Library intervenes by publishing archival materials that attest to the vibrant cultural formation of this important region of London. The Polack Archive: A Digital Edition of Fiction Without Romance (1830) and The Lyon Archive: Speculative Thinking_About a Family of Writers housed in this library focus on the powerful work of existing physical archives and the creation of digital archives that engage with extant records from the past while imagining audiences in the future.

The East End Digital Library and subsidiary archives have been in development since 2015 and correspond with The Archive's East End: Literary and Print Culture in 19thCentury London (University of Virginia Press, forthcoming 2022). A study of the intersection of critical ethnic studies, urban studies, and archival theory, The Archive's East End not only recognizes the silenced history of East End literary culture but demonstrates how the study and creation of digital archives can respond productively to cultural silences and marginalized perspectives. The audience for this project is broad and includes scholars and students of digital humanities, 19th-century 
literature, Jewish literature, archival theory, and critical ethnic studies, as well as members of the public interested in 19th-century literature and archives.

The technical infrastructure of The East End Digital Archive has been developed to facilitate collaborative work among scholars, students, and members of the public. The digital library landing page uses WordPress to enjoin two digital archives-The Lyon Archive and The Polack Archive_created with Omeka. Omeka was an ideal platform for student collaborators, most of whom lacked knowledge of programming languages. Moreover, Omeka's use of Dublin Core created opportunities for students to learn about metadata. As several student collaborators were studying public humanities, learning Omeka gave them training in a platform frequently used in library or heritage industries where they were seeking careers.

Both archives draw extensively from the collection of Omeka plugins to build projects from archival materials that are otherwise difficult or impossible to access. The Lyon and Polack families were part of the same East End social circle. While their archives are distinct from one another, references to points of overlap and interplay have been embedded in both. Links have been added throughout both archives to point to the ways in which archival boundaries separate items in individual archives while illuminating their shared cultural contexts. New sub-archives will be added to The East End Digital Library as our knowledge of the East End continues to grow.

The East End Digital Library has been created as an expanding, interactive public humanities scholarly and teaching project that has actively sought broad methods of engaging contributors and users in discussions about how to read archival objects and how debate, including dissent, can lead to broader understanding of spatial narratives and ethnic literatures in England. The Acknowledgement page on the Lyon Archive and the Acknowledgement page on the Polack Archive both point to the extensive collaborations that helped build the East End Digital Library, including students, scholars in University of Oregon Libraries, digital humanities scholars, and Lyon family members. This project bridges scholarship, teaching, and public humanities to develop a model of engagement that draws from expertise of all those involved in its production.

\title{
Project Review
}

\author{
Abigail Droge
}


The East End Digital Library: A Collection of Archives, led by Heidi Kaufman of the University of Oregon, is an exciting and imaginative project that foregrounds the robust intellectual heritage of London's East End region in the 19th century and brings archives to life for new audiences and generations by embracing what it calls "the power of speculative thinking." The vivacious way in which the East End Digital Library intertwines digital access to valuable 19th-century archives and interactive projects that respond to and extend those archives is testament to the transformative power of pedagogy when integrated with research. Indeed, evident throughout the creative decisions of the project is the foundational inspiration that Kaufman takes from her teaching practice, and several excellent examples of student work are featured. The site complements Kaufman's forthcoming book project, The Archive's East End: Literary and Print Culture in 19th-Century London (University of Virginia Press, expected in 2022), and bodes well for an exciting scholarly contribution.

A WordPress homepage leads the reader to The Lyon Archive and The Polack Archive, two linked sites powered by Omeka that build connections among artifacts, audiences, generations, and geographies. Each of these "sibling archives" showcases the intellectual contributions of a 19th-century family living in London's East End and emphasizes the centrality of Jewish thought and culture to the region's literary history. The Polack Archive chronicles the work of Maria Polack, identified as the first AngloJewish novelist, and provides digital access to Polack's 1830 text Fiction without Romance; or The Locket Watch. An exciting feature of this archive is the attention paid to the novel's paratexts, particularly the list of subscribers that appears in the British Library's copy of the text, which provides rich insight into the transatlantic scope of Polack's readership.

The Lyon Archive: Speculative Thinking about a Family of Writers is more extensive. The twin centerpieces of the site are a series of digital editions of primary documents and a suite of interactive projects. Through the digital editions, readers can engage with manuscript diaries by A. S. Lyon (1823, 1826-39), Sarah Lindo (1840), and an unknown diarist (1876) - extraordinary resources offering insight into daily 19thcentury life. The manuscripts are accompanied by extensive transcriptions, contributed by Naomi Cream and Sarah Wyer, making it easier for readers to understand the handwritten texts. Also available are digital editions of Emma Lyon's 1812 Miscellaneous Poems and Lucy Henry's 1891 volume of children's stories, The Roll Call. The digitization of such texts marks a valuable contribution to the accessibility of rare 19th-century print culture, particularly in foregrounding the writings of Jewish women. 
The interactive projects that accompany these editions are both moving and transformative. A trio of podcast interviews with family members-Annabel FosterDavis, Naomi Cream, and Diane Lyon Wead-make clear the profound impact that the Lyon Archive continues to have across generations. A "soundscapes map" adds texture to selected entries from A. S. Lyon's diary by charting mentioned locations and allowing us "to hear Lyon's writing amidst the bustling context of his London world" through short videos and sound clips. In addition, the Lyon Archive features several multimedia student essays, by Mai-Ling Maas, Rachel Elkins, Sarah Wyer, and Madeleine Jones. Such “Exhibit Essays," created through Omeka, contribute wellresearched, informative context to A. S. Lyon's diary and underscore the centrality of teaching as a core value for the project. The site also includes helpful framing materials, such as an introduction to the Lyon Archive, a biography of the Lyon family, and compelling essays on the pedagogical and technical decisions that contributed to the project's structure and ethos. The Acknowledgements page makes clear that "the work of many hands, minds, and hearts" is integral to the project.

Together, these numerous creative elements offer a broader meditation on the stakes of archival practice and succeed in the site's stated goal of "reimagining archival creation as a form of resistance against flattening stereotypes and silences in the public cultural record." This "dynamic, collaboratively developed, still-growing archive rooted in speculative fictions about place" crafts "an active forum and a performance space that invites productive exchange and experiential learning from a number of texts and participants." As Kaufman puts it, "The point is not just to value what has been saved, but to use what has been saved as a springboard for considering what's been lost."

A powerful contribution of the East End Digital Library lies in its compelling presentation of the "global dimensions of East End cultural life." The biographies of Lyon family members across multiple generations, for example, span Bohemia, England, Jamaica, and the United States. Thus, the Polack Archive "register[s]...the silent archive of slavery" in the transatlantic world. In the future, perhaps the site's extremely engaging "Soundscapes Map," which currently centers on the London depicted in A. S. Lyon's diaries, could be usefully extended to help the viewer visualize such global and cross-temporal connections. The many locations mentioned in the podcasts by descendants of the Lyon family could, for instance, be included on the map to depict intergenerational movement in geographic terms. A central map on the site's homepage could also be a powerful way to showcase the "interpretive ecosystem" of the digital library, tracking the spatial relationships among its multiple archives. 
One of the most exciting aspects of the East End Digital Library is the promise for expansion inherent in its mosaic-like structure; the layout of the site invites the reader to look forward to further archives which could be added. As the site grows, there might be an opportunity to consider the framing of the digital library as a whole, particularly in terms of establishing connections among various parts of the collection, situating the site in relation to existing scholarly and community understandings of the East End, and linking the values at the heart of the site to broader contemporary and historical pedagogical movements. The homepage, for example, could more clearly emphasize the important role played by Jewish families and authors in the East End. If the site grows to include archives from different cultural traditions, more extensive contextualizing information about the history, geography, socio-economic parameters, and demographic make-up of the region in the 19th century would be useful from the outset. In addition, the site's opening presentation of current understandings of the East End as dominated by the lurid details of Jack the Ripper could perhaps be revised to reference the work of numerous other scholars, organizations, and communitiesboth in the 19th century and today-that preserve and promote the region's intellectual life. Recognizing how the pedagogical practices and digital storytelling foundational to the East End Digital Library both complement and move beyond existing archival interventions would strengthen the project's claims. More robust contextualization and more prominent navigation features on the homepage, as well, would ensure that first-time viewers don't miss any of the site's excellent resources.

Overall, the East End Digital Library makes a valuable and inspiring contribution to the study of 19th-century print culture, motivating new audiences to engage with the archive through, in the team's words, "interpretation, dissent, and wonder." As the project states, its innovative digital archiving methods "do more than preserve objects from the past; they create a space in which to explore why those objects still matter to us today." As Annabel Foster-Davis, the keeper of the Lyon family archives who is interviewed in one of the site's podcasts, notes, "If stories aren't told, then they can't live on." The East End Digital Library is sure to enable these stories to live on for generations to come. 